\title{
THE FIFTH AORTIC ARCH OF MAMMALIAN EMBRYOS; THE NATURE OF THE LAST PHARYNGEAL EVAGINATION
}

\author{
FRANK REAGAN \\ Contribution Number 121 from the Zoölogical Laboratory of Indiana University \\ SIXTEEN FIGURES \\ PART 1
}

The question of the existence of six aortic arches in mammalian embryos has recently received much attention. In the minds of some, perhaps, it is definitely and satisfactorily settled; yet the known facts and the conclusions drawn from them are diverse and conflicting. For this reason, anything further to be added may be of interest.

The significance of the question is well understood. A demonstration of six arches would serve to bring into line the branchial circulation of mammals with that of the lower vertebrates, and to strengthen the belief in the similarity of ontogenies in related groups. By Lehmann and Locy the view has been advanced, that, upon a demonstration of the same number of arches in all air-breathing groups depends the comparability of the arches giving rise to the pulmonary arteries. This view seems altogether unnecessary since, if it be granted that mammals have only five pairs of arches, all doubt of comparability should fall on the more transitory and questionable vessels. To deny the similarity of the pulmonic arches because of a variable number of arches anterior to them, is as illogical as to doubt the identity of the systemic arches because of the fact that different numbers of arches may exist posterior to them. Because of the constancy of their characteristics, the identity of the pulmonic arches of all air-breathing vertebrates is well established. 
All workers are agreed that the transitory vessel representing a new arch is to be looked for between the fourth and pulmonic arches.

Although the results of previous observers have been rather exhaustively discussed, mention may profitably be made of points which have direct bearing on the present work.

The first evidence in favor of the predicted existence of a new arch in mammals, was adduced by Zimmermann ('89), when he found in a $7 \mathrm{~mm}$. human embryo, a small vessel arising from and re-entering the posterior side of the fourth arch. He also described a complete and typical fifth arch in an eleven day rabbit. The arch arose from the ventral aorta and emptied into the aortic root, not far from the dorsal lumen of the pulmonic arch.

Tandler ('02) found, in a rat embryo, a broad connection between the fourth and pulmonic arches, parallel to the dorsal aorta; he identified it as a fifth arch, despite the fact that it was without connection with either aorta, and that there was no corresponding pharyngeal pouch. In two human embryos he found vessels connecting the ventral aortae with dorsal portions of the pulmonic arches.

Lehmann ('05) has figured a complete arch for the pig, and has described it as follows:

A short distance from its union with the truncus arteriosus the fourth arch increases greatly in width and there is given off from its posterior side near the middle of the arch, a smaller, but perfectly distinct vessel which, bending slightly downwards, follows along the course of the fourth areh and joins the dorsal aorta immediately beneath it. Just ventral to its union with the aortic root there passes back from the rudimentary vessel, a branch which joins the sixth arch immediately ventral to its union with the dorsal aorta.

From this description we are to interpret the portion of the vessel joining the aorta as the distal portion of the arch proper, and the vessel to the pulmonic as a branch of it. These indeed would be conditions requisite to a typical arch; but Locy's interpretation of the same vessel is not in accord with the above view when he describes it as "passing dorsad and caudad to unite with the pulmonic arch near the union of the latter with the aortic root." $\mathrm{He}$ also states that "it is connected with the aortic root by an inde- 
pendent branch." This conclusion he bases on the results of previous observers and upon the other figures of Lehmann, but from her fig. 10, it must be admitted that there is as much and perhaps more ground for Lehmann's interpretation, because the blind spurs on the aortic root in that figure are more prominent than those on the pulmonic vessel.

Lewis ('06) having investigated the conditions in the rabbit and the pig, maintained that the vascular irregularities, blind spurs, and anastomosing sinuses near the bases of the fourth and pulmonic arches furnish no evidence that a typical arch exists between them. His figures afford strong evidence to support this view. He regards the attempts to demonstrate a fifth arch as "morphological speculations of extreme interest" but adds his belief that "the general recognition of a new arch in mammals seems to be due to those considerations which led Boas to predict it rather than those which come from the study of mammalian embryos themselves."

In mole embryos of 4.7, 5, 5.5, and $6 \mathrm{~mm}$., Soulie and Bonne ('08) found a number of complete vessels arising from both the truncus anteriosus and the fourth arch. Their $5.5 \mathrm{~mm}$. embryo is of interest becaue of a more typical fifth vessel. This vessel is described as "entierement distinct et isole" from the fourth and sixth arches. Its origin from the aortic bulb is given as $30 \mu$ above the ventral lumen of the fourth arch in a plane vertical to it. (From this description the ventral aorta is considered as extending dorsally and laterally to the point of origin of the fifth arch and including the common trunk of the fourth and fifth arches.) On leaving the bulbus it turns outwards, curves, and applies itself against the external face of the fifth pouch, embracing the latter in its concavity. On leaving the fifth visceral arch it turns freely to unite with the aortic root, about $80 \mu$ from the lumen of the pulmonic arch. Their $6 \mathrm{~mm}$. embryo ' $\mathrm{C}$ ' shows remarkably distinct fifth visceral arches. They maintain themsclves to have demonstrated perfect fifth aortic arches (regarding those connected with the pulmonic as typical), but admit that the work of other observers may profitably be annexed to their own. 
In a dicephalous lamb, three or four weeks after its birth, a vessel suggesting a fifth arch was found by Bishop ('08). It was seen as a slender sinus, connecting the two component aortic trunks. Since the more stable arches, as such, had either degenerated or become greatly modified, and since the vessel had no connection with either aortic root, it affords rather uncertain evidence of a fifth arch.

In cat embryos, Coulter ('09) found spurs and sinuses which he suggests as rudiments of a fifth vessel, but in no case did he find a complete arch.

If we are to be so exacting as to demand of this new arch, those qualifications and characteristics common to other arches with which we attempt to prove the vessel homologous, it will be seen that the only typical fifth arches yet demonstrated, are those of the eleven day rabbit of Zimmermann, and of the 5.5 mm. mole of Soulie and Bonne. These are described as typical in that they were said to connect the aortae and occupied distinct visceral arches. But the description of the vessel in the Zimmermann embryo was unaccompanied by figures; furthermore, the existence of the vessel in the rabbit has been doubted by Lewis (assent to Lewis's view has been given by Coulter). Also, from the description of the $5.5 \mathrm{~mm}$. mole of Soulié and Bonne, the ventral aorta is considered as extending to a point $30 \mu$ vertically above the lumen of the fourth arch, so that the common trunk of the fourth and fifth arches must have been interpreted as ventral aorta. This interpretation is allowable, yet an arch arising more ventrally would be more typical. From their reconstruction 'A,' the dorsal portions of the fifth vessel and the pulmonic arch seem sufficiently intimate to justify their being regarded as entering the dorsal aorta in common. The supposition is in harmony with the view of Coulter in which he, reviewing the results of Soulié and Bonne, stated that their fifth arches emptied "in every case into the dorsal aorta in common with the pulmonic arch." At any rate, this intimacy renders the arch less typical. From the foregoing consideration, a demonstration of an arch more typical than those just mentioned seems desirable, even though it be granted with Soulie and Bonne that they may have successfully demonstrated their "phylogenetic souvenir." 
Since the extreme irregularities back of the systemic arch render the existence of a typical "fifth" arch more doubtful, the following question naturally suggests itself: do such irregularities occur in connection with the other arches; if so to what extent; and is a tendency towards bi-lateral duplication of irregularities more strongly displayed in the region of the new vessel than elsewhere?

In order to determine these points and to throw as much light as possible on the probable nature of this fifth vessel and its associated pharyngealparts, a study was made of one hundred and fifty pig embryos, ${ }^{1}$ between stages of eighteen somites and $15 \mathrm{~mm}$. Most of the embryos studied were between and including the stages of 8.5 and $9.5 \mathrm{~mm}$.

In embryos smaller than $6 \mathrm{~mm}$., marked irregularities were rare. The first, second and third arches often showed blunt protuberances and rough walls. These seemed more common on each arch at the height of its development.

In an embryo of $6.5 \mathrm{~mm}$., a vessel of about one third the calibre of the fourth arch (fig. 15) was found springing from the middle of the anterior side of that arch, and returning to it near its dorsal lumen. This smaller vessel is a trifle similar to that of the human embryo of Zimmermann, except that it is found on the anterior facc of the fourth arch. The conditions in fig. 15 would indicate that the vessel described by Zimmermann was merely a division of the fourth arch.

At the stage of $7 \mathrm{~mm}$., short spurs were occasionally present near the ventral end of the fourth arch, projecting caudally. Short projections were common on all portions of the posterior face of the fourth arch. Stages of $8 \mathrm{~mm}$. showed slightly more irregularities in the region of the fifth vessel than in the preceding stage. In a few $8.5 \mathrm{~mm}$. embryos, slender dorsal connections

${ }^{2}$ I am much indebted to Professors C. H. Figenmann and F. Payne for direction and helpful criticism of the work undertaken. Acknowledgment of indebtedness is also due Professor Frank R. Lillie for permission to consult the cmbryological collection of the University of Chicago, and Professor C. H. Spurgeon of Drury College, for the use of his excellent private collection. Besides the embryos of these collections, those of the embryological cabinet of Indiana University, a number of series of my own preparation, many student preparations were also examined. 
between the fourth and pulmonic arches were observed. Projecting into the dorsal aorta and sometimes piercing it, "islands" of mesoderm were often found. There was a slight tendency towards a duplication of these conditions on opposite sides.

An $8.6 \mathrm{~mm}$. pig (measured after having been killed in Zenker's fluid and dehydrated), number 78.S of the C. H. Spurgeon collection, is of unusual interest because of the remarkably well developed fifth arch. The vessel exists typically on the right side without dorsal connection with either of the neighboring arches.

Figs. 6 and 7 are from wax reconstructions of the branchial circulation of the embryo. They were made by the method of Born. The cavitics of the arches are represented as solid. The entodern of the pharynx and the ectodern of a portion of the body wall are represented as such. In maintaining perspective, some parts of the model may appear to have been drawn out of proportion, but apparent discrepancies will be accounted for by a comparison of figures. In fig. 7, for instance, the intimacy of the fifth vessel with the ventral aorta would seem exaggerated, since it is impossible to show the extent of the ventral aorta in a lateral view. On the other hand, fig. 6 hardly does justice to this intimacy since the ventral divcrticulum of the third pharyngeal pouch conceals the point of diversion of the third and fourth arches. The origin of the fifth arch, however, is definitely located when the sections (figs. 1 to 5) are consulted.

Fifteen microns lateral to the plane containing the point of diversion of the third and fourth arches, the most median and ventral indication of the fifth vessel is seen as a low ridge ${ }^{2}$ (fig. 5) on the ventro-caudal surface of the ventral aorta. ${ }^{3}$ The ridge increases in size and follows for a very short distance the course of the ventral aorta laterally and dorsally. Continuous with

${ }^{2}$ After the completion of the reconstruction another small island of mesodern was found in this ridge, but is not shown in Fig. 6 .

${ }^{3}$ The common trunk of the fourth and fifth arches lateral to the diversion of the third and fourth arches may still be considered as ventral aorta for the following reasons: (1) the distance is only 15 microns; (2) for the same reason that the common trunk of the third and fourth arches isalways regarded as ventral aorta; (3) greater intimacy of the arches is allowable at their points of origin than at their places of termination since they must all arise from a common centre, necessitating the existence of eommon trunks. But in no instances do the more stable arches normally enter the dorsal aorta by common trunks. 
this ridge the fifth vessel has its origin. It curves freely in a latero-dorsal and at the same time, caudal direction (fig. 7), passing between the glandule thyroidienne and the "prepulmonic caecum.' ${ }^{\prime}$ From this point, the fifth vessel curves rather abruptly towards the median line. Just ventral to its union with the aortic root, the vessel increases greatly in size; this increase is more prominent on the posterior surface (figs. 1 and 7). Opposite this prominence ${ }^{5}$ is a slight outbulging on the anterior face of the pulmonic arch. The mesenchyme is continuous between the two vessels (fig. 1). The dorsal lumen of the fifth vessel is situated about midway between the systemic and pulmonic arches, (figs. 1 and 7 ).

The left side of the same embryo (fig. 10) has only the rudiments of a fifth arch. The vessel seems to have lost its original and most ventral connection, and has formed a second one higher up on the fourth arch. The portion between this and the original connection has partly degenerated. There are dorsal connections with the adjoining arches somewhat similar to those in fig. 8. (In both instances the pulmonic connection is the smaller.) These dorsal branches have persisted and probably represent the connecting sinus found by Tandler in the rat. I have found dorsal connections between the fourth and pulmonic arches in about thirty-five instances in which the dorsal connection varies from a very slender to a broad connection where the fourth and pulmonic arches apparently come in contact (fig. 14). The very slender connections seldom have direct connection with the dorsal aorta.

The $9 \mathrm{~mm}$. sagittal series Number 1299 of the University of Chicago collection is of much interest because of a complete fifth vessel (fig. 8). Twenty microns lateral to the plane of diversion of the third and fourth arches, there is seen on the ventro-caudal surface of the ventral aorta (somewhat similar in position to the vessel on the right side of the preceding embryo) a prominent

4 For the significance of this term, see part 2.

' On the postero-dorsal surface of the systemic arch is also a small prominence of about the same size. These probably indicate the beginning of branches of the fifth areh. 
ridge. After coursing dorsally and laterally $30 \mu$ from its most median indication, this ridge abruptly gives off, continuous with its extremity a fifth vessel which, after a very short ventro-caudal course makes a right angle turn in a dorso-caudal direction, curving at the same time laterally. After passing between the much attenuated glandule thyroidienne and the broad 'pre-pulmonic caecum, the vessel curves in a dorso-median direction and joins the dorsal aorta not far from the dorsal lumen of the fourth arch. But just before uniting with the dorsal aorta, the fifth vessel gives off two branches neither of which has so great a diameter as that of the fifth vessel at this point. The smaller of these two branches passes in a caudal direction and joins the pulmonic arch near its dorsal lumen. The larger branch lies practically opposite the branch just described; it passes anteriorly to join the systemic arch just ventral to the union of that vessel with the aortic root.

The conditions of this embryo are suggestive of those seen in Lehmann's fig. 12. Their points in common are: that in each case the fifth arch has a branch communicating with the pulmonic arch; these communications leave (or perhaps enter) the fifth arch at about the same angle; the anterior portion of each pulmonic connection is relatively small, while the posterior portion of each is large and flaring. The last fact may be suggested as indicating the connection to have originated from the pulmonic arch. My figure differs from that of Lehmann, in that the fifth vessel of my fig. 8 is more intimately connected with the ventral aorta; the portion entering the aortic root is much larger than the pulmonic branch. These conditions indicate that Lehmann was correct in interpreting the pulmonic connection in her fig. 12 as a branch of the fifth arch. My fig. 9 is made from a reconstruction of a $9 \mathrm{~mm}$. embryo. The rudiment of the fifth vessel has a systemic connection, but is in no way connected with the pulmonic arch. These conditions also point to the correctness of Lehmann's conclusions.

Stages later than $9 \mathrm{~mm}$. exhibit irregularities in abundance, but they gradually become less typical. In a $10 \mathrm{~mm}$. embryo, a pulmonic arch was seen as a $\mathrm{Y}$-shaped vessel. A long finger- 
like projection extended down behind it from the dorsal aorta. Blunt protuberances were found similarly located in three instances.

Figs. 11, 12 and 13 show irregularities slightly suggestive of a fifth arch, but they are situated so far dorsally and laterally that they need not be considered seriously. Also, they form such straight and direct communications, lacking the curvature found in the typical arches, that I consider it mere conjecture to suggest their having significance. Granting with Locy that irregularities such as these serve to demonstrate the extreme variability of the supposed vessel, it must be admitted that these, and those to which he had reference cannot at the same time prove a typical existence for the new arch.

On the grounds of majority it has been held that a perfect fifth arch has, for its distal termination, the dorsal extremity of the pulmonic arch. It was this consideration that led Locy to oppose the view of Lehmann (above stated and confirmed). But it is evident that, in the pig at least, the fifth arch connects the two aortae and lies between successive pharyngeal evaginations; hence it conforms to the requisites of a typical arch. It may be that conditions other than these represent the highest degree of development attained to by certain forms, but such forms can not be said to exhibit it in a theoretically typical manner. On the other hand, it is only to be expected that the vessel in question generally be found in an a-typical condition and very exceptionally perfect. Therefore an occasional constancy in atypical conditions should not be allowed to dominate our conception of a theoretically perfect arch.

The relatively late appearance of the supposed fifth arch is another point which believers in that vessel have seen fit to neglect. This point receives consideration in Part 2. 


\section{PART 2}

The double pharyngeal out-pocketing found back of the systemic arch is not well understood. At present there are three views concerning its significance: (1) that the double outpocketing represents the fourth pharyngeal pouch with its dorsal and ventral diverticula (Fox, Tandler, Coulter); (2) that the dorsal and ventral parts of the outpocketing represent the fourth and fifth pouches respectively (Greil, Zimmermann); (3) that the ventral portion represents the postbranchial body of lower vertebrates (Mauer, Verdun). From these considerations the ventral portion of the double outpocketing has been designated by the following terms: (1) ventral diverticulum of the fourth evagination; (2) fifth branchial pouch or ultimo-branchial body; (3) post-branchial body. Since no one of these terms is sufficiently general to cover all the views presented, the term 'pre-pulmonic caecum' might be suggested. This term is applicable to the ventral division of the out-pocketing, whatever may be its significance. The further usefulness of the term is shown later.

This much, however, is definitely settled: the dorsal portion of the double pouch is the anlage of the 'glandule thyroidienne' of Prenant, while the 'pre-pulmonic eaecum' becomes the rudimentary lateral thyroid.

According to Verdun the development of the last pharyngeal evagination (or evaginations) is as follows: the pre-pulmonic caecum is first given off as a latero-ventral diverticulum, posterior and mesial to the third pouch. Near the dorsal extremity of the caecum, and slightly anterior to it the "glandule thyroidienne" is given off immediately from the pharynx as an independent diverticulum. Both push out laterally, drawing with them the wall of the pharynx lying between their bases. Thus they acquire secondarily a common pharyngeal orifice. Their formation differs in this last respect from that of the pouches anterior.

Fox ('08) in describing the posterior evagination of a $6.5 \mathrm{~mm}$. pig; gave the location of the 'dorsal portion of the fourth pouch' as posterior and dorsal; he gave the 'ventral portion' as anterior and ventral. This may have been due to his considering directions with reference to the general contour of the embryo, and not with reference to the direction of the pharynx where the evagination joins it. 
In the rabbit and the pig the glandule thyroidienne is generally considered anterior to the pre-pulmonic caecum.

The posterior evagination in the cat is figured by Coulter as having dorsal and ventral portions, the dorsal portion having become constricted into anterior and posterior divisions. The anterior division is more directly continuous with the ventral portion, and is labeled the dorsal diverticulum of the fourth pouch. The posterior division is represented as the fifth pouch. If the entire dorsal portion of the evagination be considered anterior, as in other forms, the fifth pouch of the cat would be morphologically anterior to the ventral diverticulum of the fourth pouch. If as stated by Verdun (and as I have observed in a limited study of the development of the evagination in the pig) the earliest indication of the $\mathrm{Y}$-shaped pouch is its ventral portion, Coulter erred when he labeled the most caudal pharyngeal prominence of his $4.5 \mathrm{~mm}$. cat as 'pouches $4-5$.'

The 'glandule thyroidienne,' like the pouches anterior to it, comes in contact with the ectodern, differing radically in this respect from the prepulmonic caecum. Occasionally I have found it constricted into dorsal and ventral portions. In one instance (fig. 16) which is very unusual, the glandule thyroidienne is divided into dorsal and ventral portions, each of which has direct connection with the exterior through the pre-cervical sinus. Between the small diverging tubes thus formed, is the mesodermal connection presumably between the fourth and fifth visceral arches. The plane passing through the pre-pulmonic caecum is shown slightly above (posterior to) that of the glandule thyroidienne. The occasional division of the glandule thyroidienne into dorsal and ventral portions is suggestive of its representing an independent pouch.

Attention may profitably be called to the chronological relations of the portions of the double evagination to the associated aortic arches, since these relations have hitherto remained unnoticed. The 'glandule thyroidienne' and the 'fifth' arch, despite their anterior position, appear respectively later than the pre-pulmonic caecum and the pulmonic arch. (The same conditions are found in birds.) 
The dorsal portion of the $\mathrm{V}$-shaped evagination would appear, then, to correspond to the transient fifth vessel, and to have lost its double nature proportionately to the degeneration of the fifth arch. The tendency towards a distinctness of division of the 'glandule thyroidienne' from the pre-pulmonic caecum closely parallels the tendency towards the development of a perfect 'fifth' arch.

The pre-pulmonic caecum, therefore, is branchial in nature to the extent to which the pulmonic vessel is a true aortic arch; what this extent is, must be determined by a more thorough study than has yet been given to the question. Both seem to have been greatly modified, if they have ever resembled closely the parts anterior which have generally been considered their homologs.

From the foregoing considerations two views are possible: (1) that the new arches so far exploited are merely irregularities which happened to be suggestive of a fifth arch but have no significance; and that the $\mathrm{Y}$-shaped evagination is simply a fourth pouch; (2) that the fifth arch occasionally exists and the intimately related pharyngeal evagination represents more than a fourth pouch. There is much to favor the latter alternative.

\section{CONCLUSIONS}

1. The vascular irregularities are more or less common throughout the branchial circulation and may in any part show a slight tendency towards bi-lateral duplication.

2. Even though this tendency is far more pronounced in the region of the supposed fifth arch, the irregularities here should be considered very reservedly, since in most instances they are merely an expression of the tendeney towards anastomosis, common to vessels in close juxtaposition.

3. A fifth vessel, very closely approximating a theoretically perfect aortic arch can be demonstrated for the pig; it may be with or without connecting branches from either the systemic or the pulmonic arch or from both. 
4. If a typical 'ffth' arch actually exists, appearing after the pulmonic arches are formed the latter vessels must be regarded as differing, to a certain extent, from the vessels anterior to them; and to this extent the branchial nature of the pre-pulmonic caecum has become modified.

\section{BIBLIOGRAPHY}

Vax Bemmenex, J. F. 1886 Die Visceraltaschen und Aortenbogen bei Reptilien und Vögeln. Zool. Anz.

Bishop, Madel 1908 Heart and anterior arterics in monsters of the Dicephalous Group. A comparative study of Cosmobia. Am. Journ. Anat., vol. $8,13$.

Boas, J. E. Ueber die Artereinbogen der Wilbcltiere. Morph. Jahrb., Bd. 13.

Cotlter, C. B. 1909 The early development of the aortic arches of the cat, with especial reference to the presence of the fifth arch. Anat., Rec., vol, 3, No. 11.

Fox, H. 1908 The pharyngeal pouches and their derivatives in mammalia. Am. Jour. Anat., vol. 8, no. 3.

Grent, A 1905 Über die Anlage der Lungen, ete. Anat. Hofte., Bd. 29.

LeHMAN, ThARRIET 1905 On the embryonic history of the aortic arehes in mammals. Anat. Anz., Bd. 26.

Lewrs, F. T. 1906 The intra-embryonic blood-vessels of rabbits from eight and one-half to thirteen days. Am. Jour. Anat., vol. 3.

1906 The fifth and sixth aortio arches and the relatcd pharyngeal pouches in the rubbit and pig. Anat. Anz., Bd. 28.

Locr, W. A. 1906 The fifth and sixth aortic arches in chick embryos, with comments on the eonditions in other Vertebrates. Anat. Anz., Bd. 29. 1909 The lifth and sixth aortic arches in birds and mammals. Cambridge, Mass.

Mater, P. 1902 Hertwig's Tandbuch der vergl. u. exp. Entwickelungslehre., Bd. 2, abt. 1 .

Prenant 1894 Développement organique et histologique du thymus, de la glande thyroide et de la glande carotidienne. La Cellule T. 10.

Soumbé, A., AND Bowre, C. 1908 L'Appareil Branchiale et les Ares Aortiques de l'Embryonen de Taupe. Jour. de l'Anat. et de la Phys. No 1.

Tandere, J. 1902 Zur Fintwickelungspesehichte der Kopfarterien bei den Mam. malia. Morph. Jahrb., Bd. 30. Anat. Hefte, Bd. 38.

Verdun, M. P. 1898 Dérivés branchiaux chez les vertébrés superieurs. Toulouse.

Zimuermann, W. 1889 Ueber einen zwischen Aorten- und Pulmonalbogen gelegenen Kiemenarterienbogen beim Kaninchen. Anat. Anz., Bd. 4. 1889 Rekonstruetion eines menslichen Embryos. 


\section{ABBREVIATIONS}

D.Ao., Dorsal aorta

Gl.t., Glandule thyroidienne

Mes.c., Mesodermal connection

Ph., Pharynx

$P h$. 1., Common pharyngeal lumen of glandule thyroidienne and the prepulmonic caecum
Pul., Pulmonic arch

Sin.pr., Sinus preacervicalis

V.Ao., Ventral aorta

$V d$. 3., Ventral diverticulum of third pouch

$3,4,5$., Third, fourth and fifth aortic arches
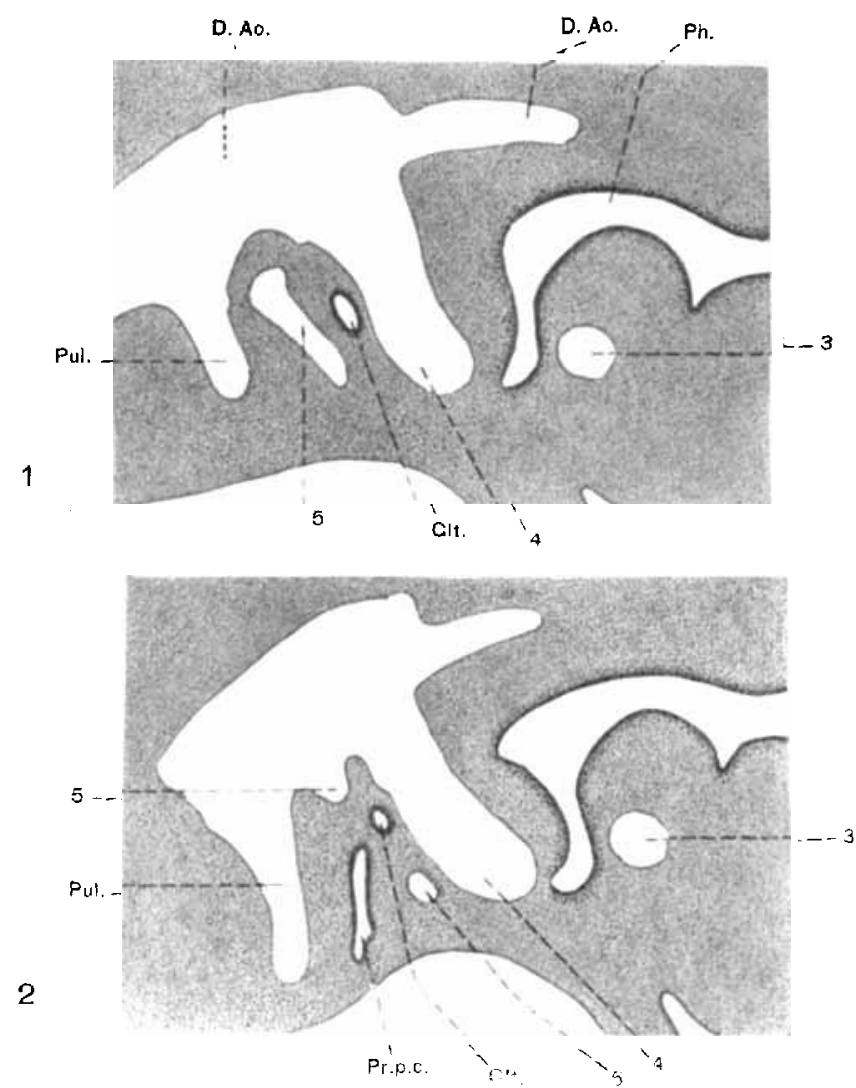

Figs. 1 to 5 Siagittal sections through the branchial region of the right side of the $8.6 \mathrm{~mm}$. pig, series no. 78.5 of the C. H. Spurgeon collection. $\times 60$.

Fin. 1 Section through tho upper portion of the fifth arch. 'The section passes through the glandule thyroidienne abont 20, median to its most lateral extremity.

Fig. 2 Section ( $40 \mu$ median to section 1 ) through the dorsal lumen of the fiftb, and passing through it not far from its middle point. (The prominence on the dorsal portion of the systemic arch is still noticeable.) 


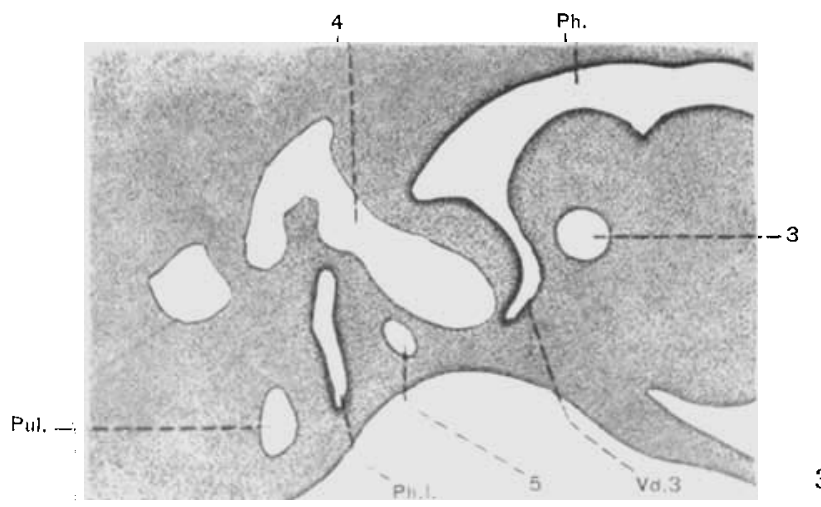

3

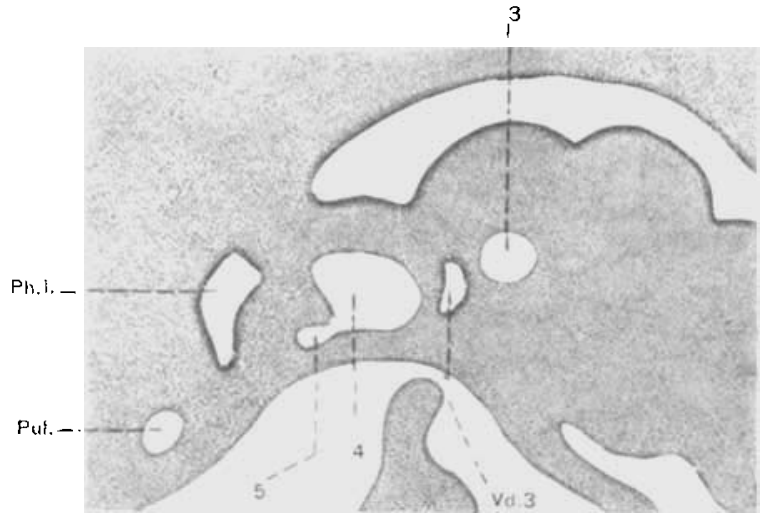

4

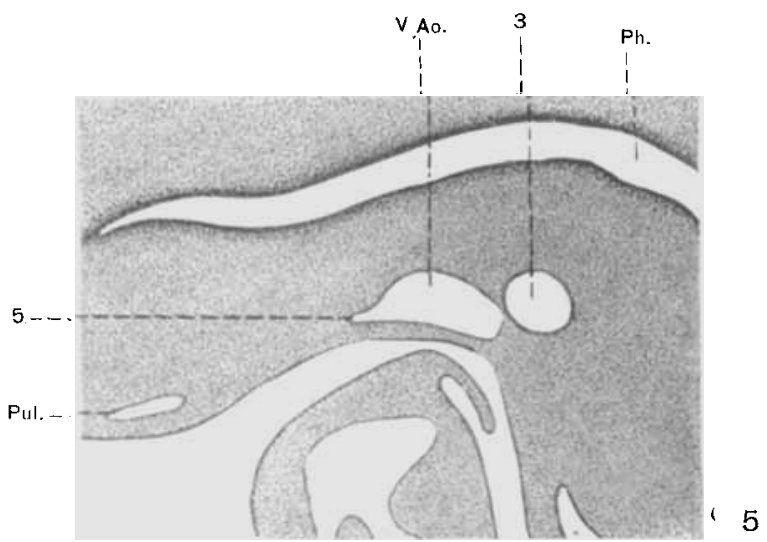

Fig. 3 Section $(20 \mu$ median to section 2$)$ through the lower part of the fifth arch, showing the eommon orifice of the glandule thyroidienne and the prepulmonic caecum.

Fig. 4 Section $(40 \mu$ median to scction 3$)$ through the ventral lumen of the fifth arch.

Fig. 5 Section $20 \mu$ lateral to the point of diversion of the third and fourth arches, showing the fifth arch about 5 from its most median indication. 
$\mathrm{PJ}_{2} \mathrm{ATTH}_{2} 1$

GXPLANATION OF FIGURA

Fig. 6 Ventral view of a wax reconstruction of the aortic arches and pharynx of the. same embryo. The body wall ectoderm is shown as partly removed from the ventral surface of the visceral arches. (The asymmetry of the figure is due to at twist in the embryo). 


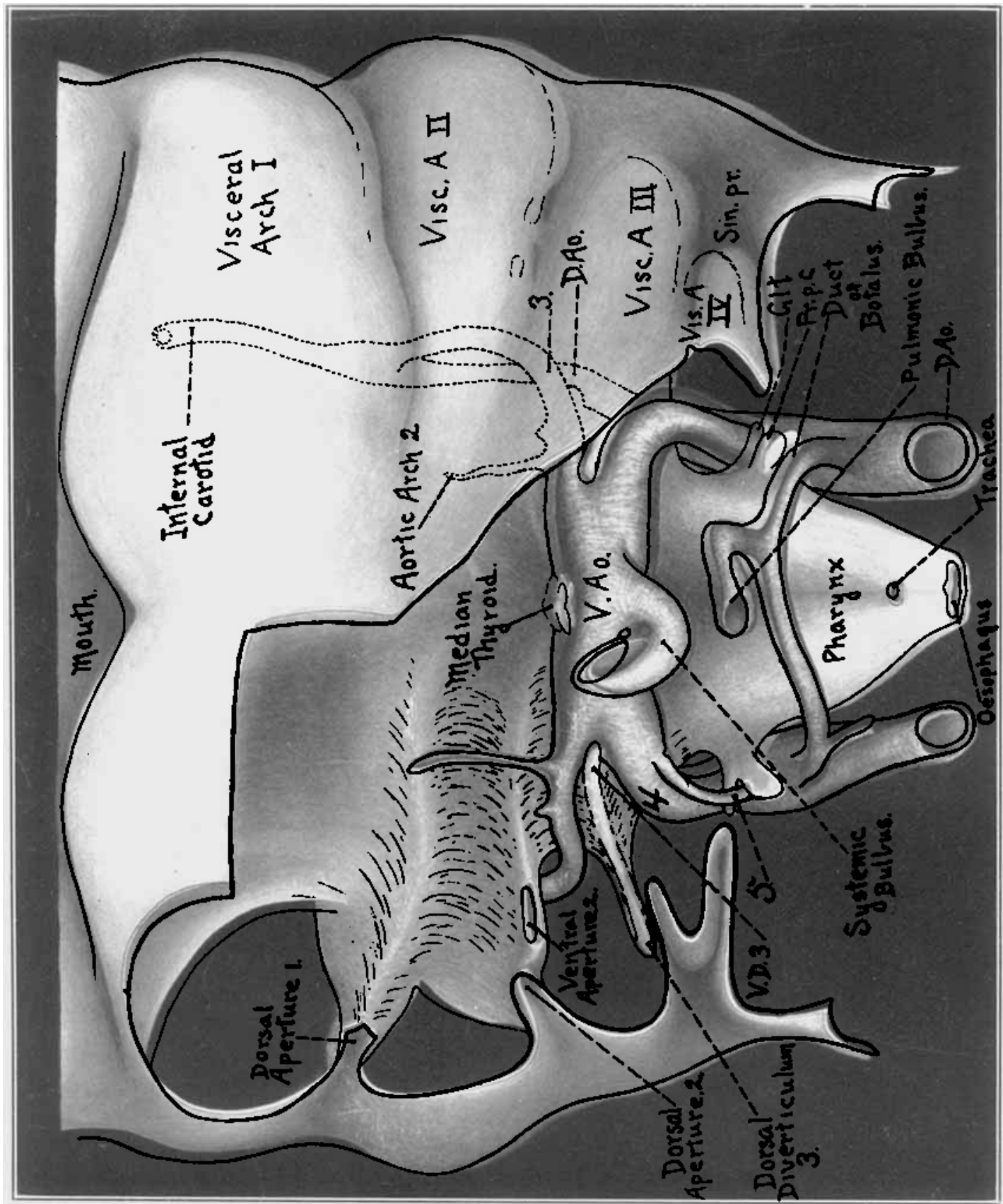


PIATH 2

EXPLANATION OF FIGURF

Fig. 7 Right-lateral view of a wax reconstruction of the aortic arches and pharynx of the same embryo. (The body wall in this model was removed differently from that of the model of fig. 6). 


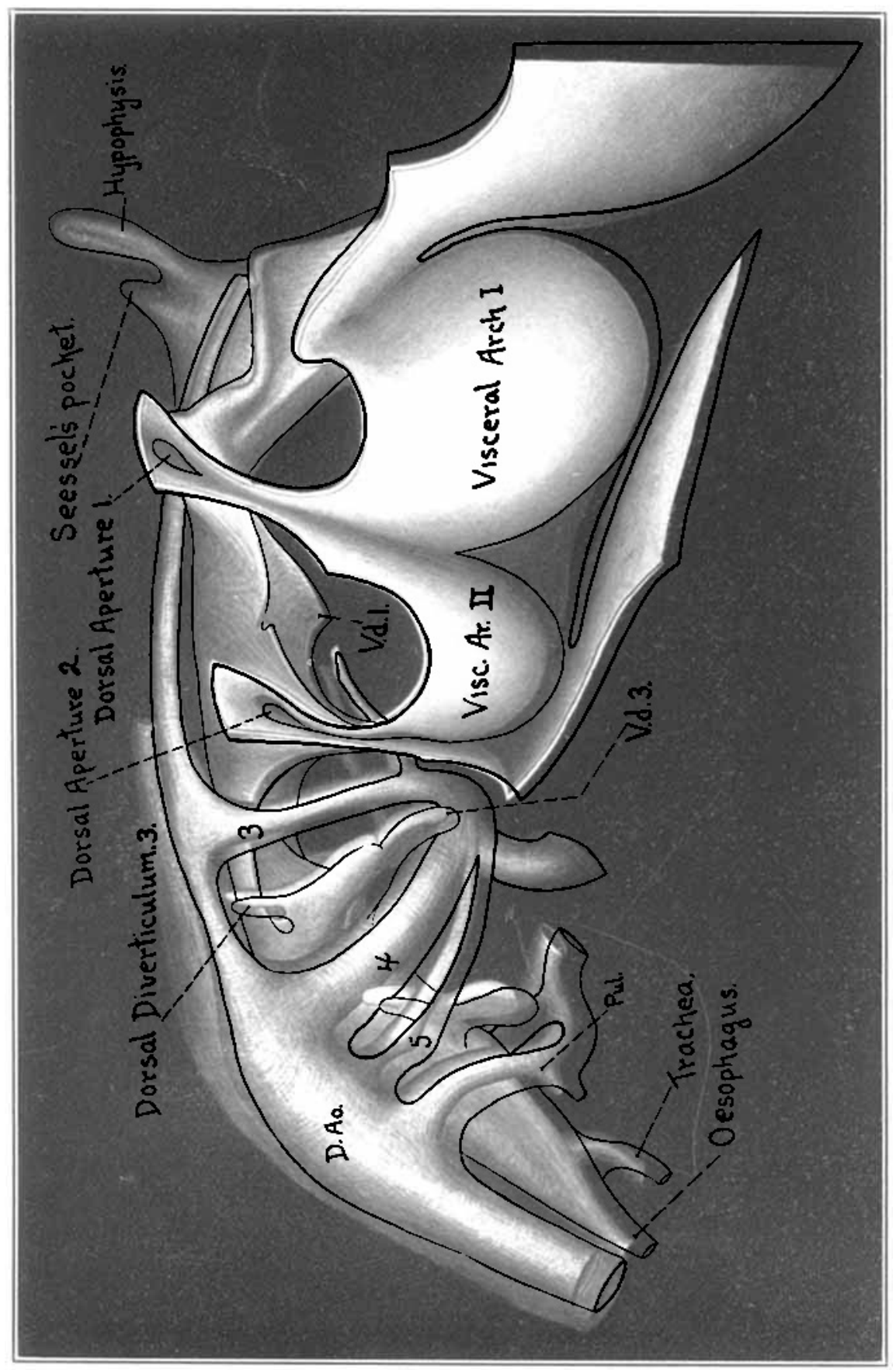




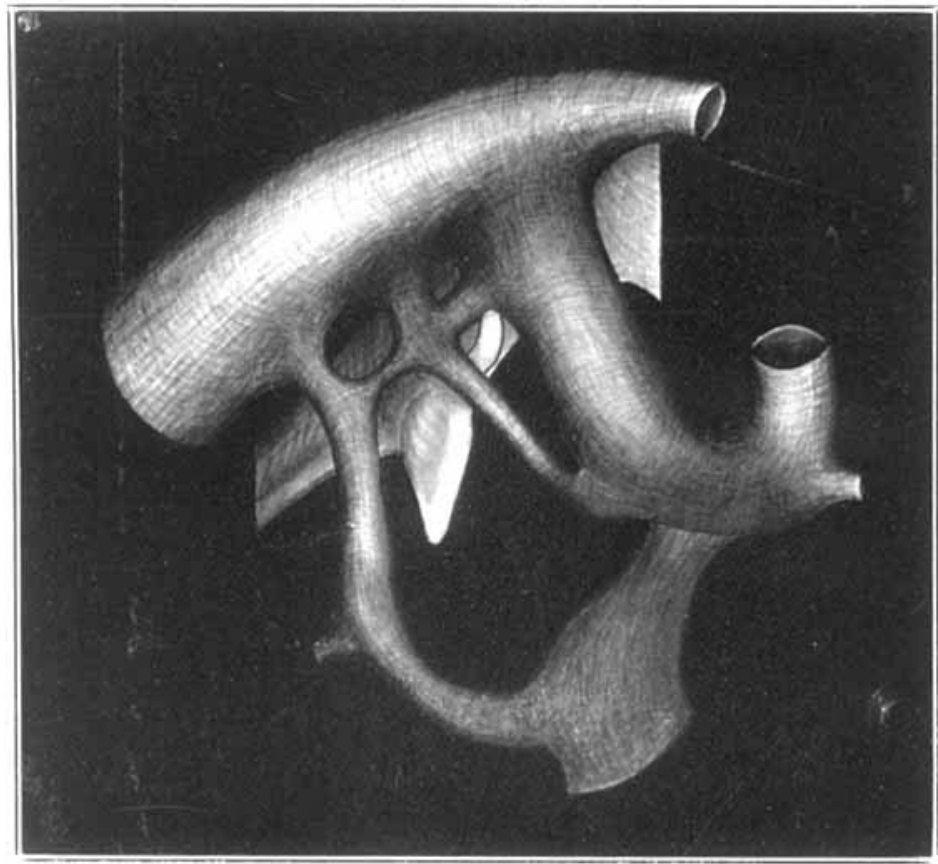

Iig. 8 Reconstruction of the aortic arches of the right side of a $9 \mathrm{~mm}$. pig Series no. 1299, University of Chicago collection. 


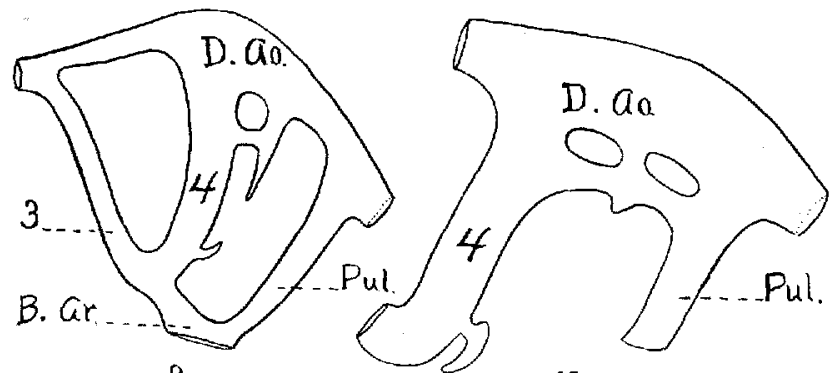

10

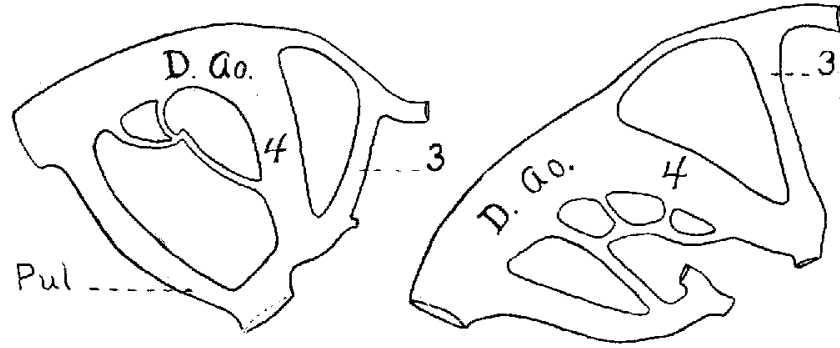

11

12

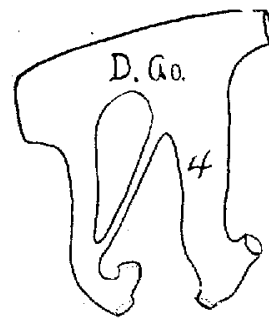

13

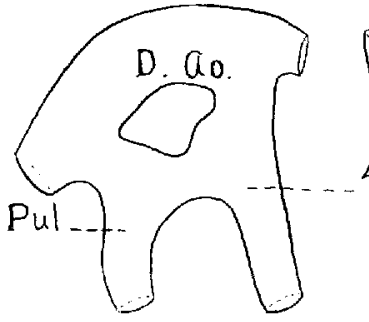

14

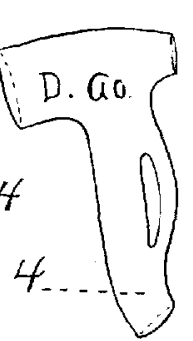

15

Fig. 9 The aortic arches of the left side of an $8.5 \mathrm{~mm}$. pig. (The development of e rudimentary vessel seems to have been impeded by the common base of the ndulethyroidienne and the pre-pulmonic caccum).

ig. 10 The left fourth and pulmonic arches of the $8.6 \mathrm{~mm}$. pig. No. 78.S of se C. H. Spurgeon collection. (No attempt was made to illustrate these conditions in figs. 6 and 7. )

Fig. 11. Aortic arches of the right side of a $9.5 \mathrm{~mm}$. pig, showing irregular conditions

Fig. 12 Aortic arehes of the right side of a $10 \mathrm{~mm}$. pig, showing unusual conditions.

Fig. 13 The fourth and pulmonic arches of the right side of a $10 \mathrm{~mm}$. pig, showing the connection betwcen the base of the pulmonic and the dorsal part of the fourth. (Conditions similar to this were observed in three instanees).

Fig. 14. The fourth and pulmonic arches of a $9.6 \mathrm{~mm}$. pig, showing a broad connection between the dorsal portions.

Fig. 15 The fourth arch of a $6.5 \mathrm{~mm}$. pig, showing a division of that vessel on its anterior face. 


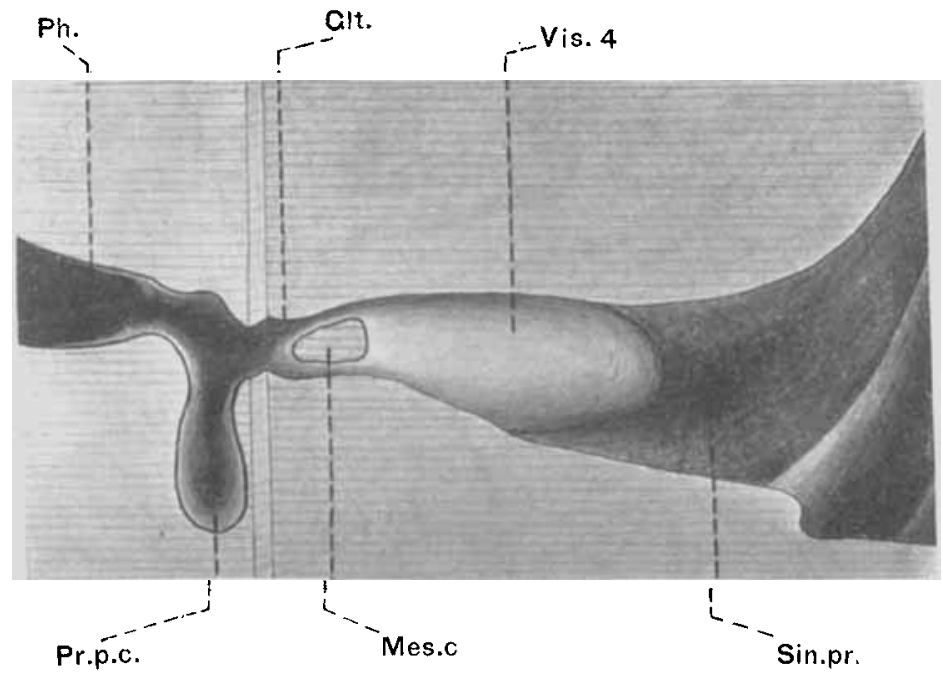

lig. 16 Reconstruction of the glandule thyroidienne and the pre-pulmonic caecum of an $8 \mathrm{~mm}$. pig. The planes of the cut surfaces (represented as striater arcas in the figure) are practically frontal. The lower (i.c., more anterior) plar passes through the glandule thyroidienno. The upper (posterior) plane passes through the pre-pulmonic caceum. The figure is slightly diagramatie.

\section{ADDENIDUM}

I regret very much to say that the excellent work of Reinke (F. F. Reinke Anatomical Record, December 1910) had entirely escaped my notice until the present work was sent to press. On the whole, his results agree very closely with my own. The fifth arch of his $6 \mathrm{~mm}$. pig seems more degenerate than that of my figures 1 to 7 . It may be questionable that the vessel had existes! at all more typically than at the stage at which the embryo was killed ventral origin is perhaps from a more dorsal point; from his fig. 2, the rat a of the fifth arch secms relatively smaller, and its contour is less regular. "n conditions in general, support admirably my contention that the fifth $v:$ does not csentially have the dorsal extremity of the pulmonic arch fo distal termination, since the connection with the aortic root is much the lit The double nature of the glandule thyroidienne of Reinke's fig. 1 (la a Pouch four) strongly suggests its comparability to the anterior pouches. In a few instances I have observed the presence of five ectodermal grooves, but the parallelism between these and the presenee of a fifth vessel does not seem constant.

Even with an additional consideration of this valuable contribution, I still believe the existence of a new arch to be somewhat questionable, although there is much evidence in favor of it. 